\title{
Cup lump modified asphalt mixture along jalan Kuala Lumpur-Kuantan, daerah Temerloh, Pahang
}

\author{
Zainal Othman ${ }^{1}$, Mohd Rosli Hainin ${ }^{2, *}$, Muhammad Naqiuddin Mohd Warid ${ }^{2}$, Mohd \\ Khairul Idham ${ }^{2}$ and Siti Nur Naqibah Kamarudin ${ }^{2}$ \\ ${ }^{1}$ Road Engineer, Jabatan Kerja Raya Perak, Malaysia \\ ${ }^{2}$ Faculty of Civil Engineering, Universiti Teknologi Malaysia, 81310 Johor Bahru, Johor
}

\begin{abstract}
Issue of rubber additive in asphalt mixture has been discussed in asphalt industry Malaysia and its usage was suggested to be used in Pan Borneo Highway project. Using rubber additives can increase revenue rubber tappers in Malaysia. Hence, a study was conducted by the Public Works Department (PWD) and Malaysian Rubber Board (MRB) to investigate the properties of Cup Lumps Modified Asphalt (CMA) based on PWD specifications and its performance. The study area selected was at FT02, Jalan Kuala Lumpur - Kuantan, Temerloh Pahang. In this study, $5 \%$ Cup Lump Modified Binder (CMB) were used. Tests involved were Penetration Softening Point, Flash Point, Dynamic Shear, Marshall, Road Scanner (RS), Falling Weight Deflectometer (FWD), Skid Resistance (Pendulum Test) and Dynamic Creep. The results indicate that CMB with bitumen 60/70 meet the specification. However, it will tend to rut when the temperature exceeds $70^{\circ} \mathrm{C}$. For CMA mixture, it shows similar performance with conventional mixture. Meanwhile, at site, the performance for CMA pavement was better in surface condition (94\% good condition in roughness), structural condition (100\% good condition), skid resistance (SRV 63) and dynamic creep (32.01 MPa) compared to conventional pavement AC14. Thus, it can be suggested that the performance of CMA is better than conventional mixture AC14.
\end{abstract}

\section{Introduction}

Hot Mix Asphalt (HMA) is a conventional mixture in road construction that are highly viscous, black, sticky, soluble in carbon disulphide and composed primarily of highly condensed polycyclic aromatic hydrocarbons which provide better in flexibility [1]. Materials for asphalt paving and standard structures must be complied with the requirements of standard specified by Highway Department in order to be sure that it's suitable to utilize and last long whilst highly safe for the users. However, HMA shows limitation on temperature, soften when the temperature is high and cracked when the temperature is low causing oxidation of asphalt because of aging process [1-3]. In addition, heavy traffic,high

\footnotetext{
*Corresponding author: mrosli@utm.my
} 
loading weight and wet tropical climatic conditions will damage the roads although these pavements are still in service cause large expenses for maintenance due to pavement distress [4]. Therefore, it is necessary to improve the quality of asphalt by the material to improve the viscosity and elasticity, diminution of temperature susceptibility, higher softening point and aging resistance and ameliorate of cohesion.

The improvement of asphalt to have those properties with various methods is continually carried on and the practical one is using polymers to mix in asphalt that is called "Polymer Modification Asphalt". Rubber is a kind of polymers using for modifying the asphalt properties. Moreover, a number of notable studies are conducted worldwide to explore an alternative resource as an asphalt substitute and replace petroleum asphalt as the conventional binder which becoming increasingly scarce as a non-renewable resource [5].

Some properties that are advantages such as stability, elasticity and fatigue resistance will be the better supplementary to asphalt properties and to extend aging of roads which can be help to save budget of maintenance. The use of rubber in bituminous materials became of interest to the paving industry because of the potential to improve durability, skid resistance and permenant deformation since 1960s [6-7]. Other than that, Stryrene Butadiene Styrene (SBS), crumb rubber, chemical additives and engineered binders are modifiers but mostly high cost materials [8-9].

Malaysia is seeking to use rubber in the building of up to $1,000 \mathrm{~km}$ of road projects this year, in an effort to increase domestic consumption of rubber as the commodity price has fallen to multi-year lows. The move will help mitigate over supplied conditions and improve prices. The roads will be contructed using rubber cup lumps, a common name for naturally coagulated latex, which will be processed into bintuminous cup lumps and then mixed into asphalt, instead of tar, the more common road making ingredient. Some 4.2 tonnes of cup lumps will be used for each kilometres of road, which indicates an estimated 42,000 tonnes of rubber would be diverted for this purpose. The rubber will be initially used for state roads and farm roads, one official with knowledge of the matter said.

Since 1843, synthetic and natural polymers are being used in bitumen as modifier but limited because of its high cost in late 1970s [10-11]. The concept of adding rubber into bitumen is more than 100 years old. The first attempt was made in 1898 by de Caudenberg who patented a process for manufacturing rubber - bitumen. However, many difficulties were encountered in exploiting the patent and the process lapsed before 1914 [12].

While the rubber industry had been using bitumen to modify rubber for various purposes, no further progress was made in the modification of bitumen by adding rubber until rubber in granular or powder form was developed in 1930. The earliest experiments in 1840s had involved incorporating natural rubber into asphalt binder to increase its engineering performance properties. The process of asphalt modification involving natural and synthetic rubber was introduced as early as 1843 [13]. In 1923, natural and synthetic rubber modifications in asphalt were further improved [14].

In Malaysia, the use of rubber as an additive for road pavement construction supposedly started in the 1940s, but there has not been any official record of such practices. The first recorded trial using rubberised bitumen technology was reported in 1988, the wet mix process was used with the mix of rubber additives in the form of latex into bitumen binder [15]. In 1993, another rubberised road trial using waste gloves and natural rubber latex was carried out in Negeri Sembilan [16].

Trials using rubberised bitumen were initiated in 1950s when 100 yards of road between Kota Bharu and Kuala Krai was laid with 5\% rubber powder. Following that, several other trials were laid in the states of Kedah, Perlis, Kelantan, Johor, Negeri Sembilan and Melaka. Unfortunately, none of these trials was monitored closely and as such no details are available.

The Polymer Modified Asphalt or PMA is one of such improvement by mixing polymers in asphalt [1]. Natural rubber is an interested polymer that can be efficiently used and could 
improve stability, elasticity, and fatigue resistance [5-6]. Their aim is to find the appropriate ratio of asphalt and rubber, which can achieve specifications required. The experiments were carried on by adding Ribbed Smoked Sheet (RSS) of 0, 2, 4, 6, 8 and $10 \%$ by weight in asphalt and using high shear mixer. Asphalt qualities were investigated in penetration, softening point, penetration index, ductility, torsional recovery, toughness-tenacity, and viscosity.

It was found that $6 \%$ by weight of natural rubber in asphalt is the most effective ratio to develop low penetration, high softening point, high penetration index, high torsional recovery, and high toughness - tenacity. The road using this mixing rate shows high strength and resistance, whilst increasing of viscosity does not cause the problem in aggregation of asphalt-concrete.

Mixing asphalt with rubber has been tested for a long time. Improvement of asphalt properties using fumigated rubber to reduce molecule by dissolving rubber into Fluxing oil until it became to Liquid Natural Rubber (LNR), and had been mixed with asphalt cement by heating [8]. Two kinds of asphalt cements were investigated which are penetration grade and blown grade. Another factor was the ratio of rubber to asphalt used to mix. The properties experimented were penetration, ductility, softening point and viscosity. It was found that adding LNR provided reduction of ductility and increased the softening point.

There were many advantages of using polymer modified bitumen which were better resistance to rutting, thickness bitumen coating, longer time to become brittle through oxidation, better durability and more elastic. From Figure 1, testing shows that Polymer Modified Asphalt is better in rutting resistance compared to normal asphalt.

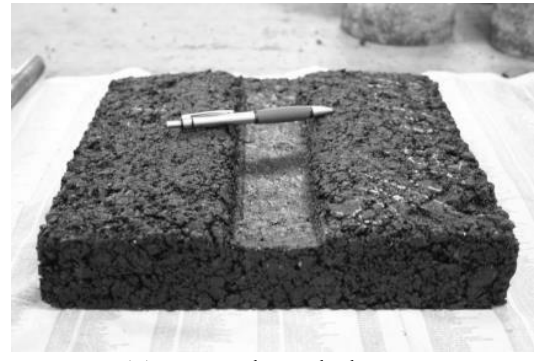

(a) Normal Asphalt.

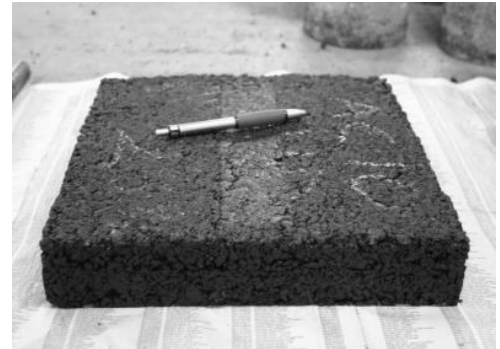

(b) Polymer Modified Asphalt.

Fig. 1. Elastic Comparison.

Moreover the increasing of traffic volume causing permenant deformation which are rutting and fatigue cracking. Thus, cup lumps one of the modifier is worthwhile for a sustainable road infrastructure and improve the binder mix properties [9].

Cup lump is a blanket crepe rubber produced from the dries films and lumps of rubber found in the tapping cups at the beginning of the next tapping. Cup Lump is more accessible than rubber taper as it does not require complicated processing than the rubber sheets and rubber latex. The market price was relatively easy compared to other products. Production of CMA underwent three phases, for phase one, fresh cup lump was added with bitumen 60/70 to produce $\mathrm{CMB}$. After that, $\mathrm{CMB}$ was added with aggregate $\mathrm{AC} 14$ to produce $\mathrm{CMA}$.

Therefore, this aims for this study were to determine the properties of Cup Lumps Modified Bitumen (CMB) and Cup Lumps Modified Asphalt (CMA) mixture based on Public Works Department (PWD) specifications and to evaluate the performance of the CMA pavement on the site. For preparation of CMA, the production of raw materials $\mathrm{BC}$ and $\mathrm{CMB}$ were mixed at the plant. For testing, bitumen testings and asphalt testings after construction were conducted. 


\section{Methodology}

The study was conducted at Jalan Kuala Lumpur - Kuantan (FT02), Daerah Temerloh, Pahang. To produce CMB, $50 \%$ of fresh cup lump was added with $50 \%$ of bitumen $60 / 70$. After that, $5 \%$ of CMB and $95 \%$ of aggregates were mixed to produce CMA. In this study, Penetration, Softening Point, Flash Point, Marshall and Dynamic Shear test were carried out at the lab while Road Scanner (RS), Falling Weight Deflectometer (FWD), Skid Resistance (Pendulum Test) and Dynamic Creep were performed on site after one month of construction.

The length of construction site study was one kilometre as shown in Figure 2 with an average width of 7 meters of single carriageway.

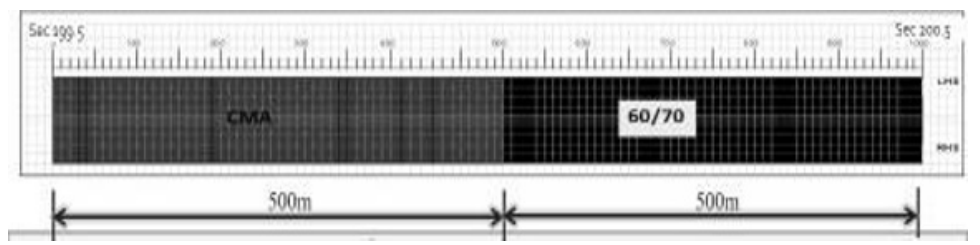

Fig. 2. Site study strip map Laluan FT02.

The construction method used the Mill and Pave $(50 \mathrm{~mm})$ while wearing course used CMA $(50 \mathrm{~mm})$. The construction site was one kilometer width where $500 \mathrm{~m}$ construction for CMA pavement and 500m construction by bitumen grade 60/70 for Control Section as shown in Figure 3.

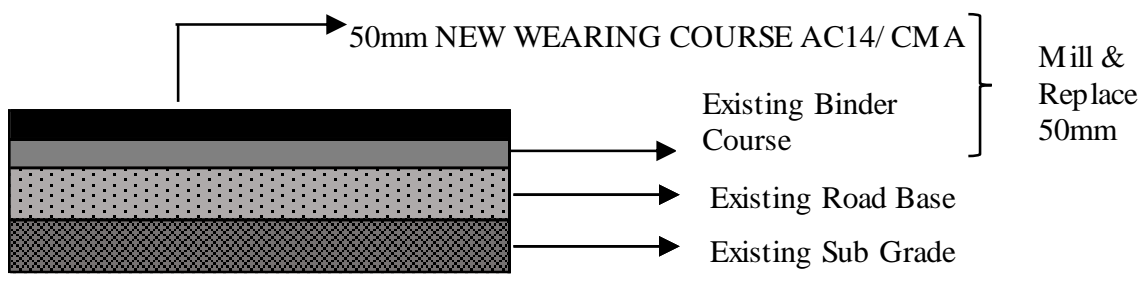

Fig. 3. Asphalt pavement layer structure.

\section{Results and Discussion}

\subsection{Result for Bitumen Testing}

For $\mathrm{CMB}$, there is no specific requirement provided by PWD. Thus, the results were compared with Perfomance Grade PMB (PG76) modifier to evaluate the performance. Table 1 shows the summary result for CMB. The results decribe that only Dynamic Shear Test (min $2.20 \mathrm{kPa}$ ) did not achieve the minimum requirement. It means that the minimum temperature for rutting resistance for $\mathrm{CMB}$ is $70{ }^{\circ} \mathrm{C}$ and more than that it failed. For overall analysis, the performance for CMB is quite similar with performance of PG76.

Table 1. Summary of CMB Testing.

\begin{tabular}{|l|c|c|c|c|c|}
\hline \multirow{2}{*}{ Parameter } & \multicolumn{2}{|c|}{ Type of bitumen } & \multicolumn{3}{c|}{ Requirement } \\
\cline { 2 - 6 } & CMB & $60 / 70$ & PG76 & $60 / 70$ & Remarks \\
\hline Penetration & 60.3 & 60.7 & - & $60-70$ & $/$ \\
\hline Softening Point & 63 & 52 & Min 60 & $49-56$ & $/$ \\
\hline
\end{tabular}




\begin{tabular}{|l|c|c|c|c|c|}
\hline Flash Point, min & 285 & 268 & 230 & & $/$ \\
\hline $\begin{array}{l}\text { Test Temperature at Dynamic } \\
\text { shear, G*/sin } \delta \text { min } 1.00 \mathrm{kPa}\end{array}$ & 76 & - & 76 & & $/$ \\
\hline $\begin{array}{l}\text { Test Temperature at Dynamic } \\
\text { shear, G*/sin } \delta \text { min } 2.20 \mathrm{kPa}, \\
\text { (After RTFO) }\end{array}$ & $\mathbf{7 0}$ & - & $\mathbf{7 6}$ & & $\mathbf{X}$ \\
\hline Loss on heating & 0.06 & - & Max 1.0 & & $/$ \\
\hline
\end{tabular}

Table 2 shows the summary for CMA mixture for Marshall Analysis and comparison with AC14 (bitumen 60/70). The result shows that CMA mixture is fulfill the specification provided by PWD. There is no significant different when compare the performance with conventional mixture. It means that the performance of CMA is able to comparable with conventional mixture.

Table 2. Summary of CMA mixture for Marshall Analysis.

\begin{tabular}{|c|c|c|c|}
\hline Parameter & $60 / 70$ & CMB & Requirement \\
\hline Stability (N) & 13050 & 13200 & Min 13000 \\
\hline Flow (mm) & 3.20 & 2.85 & $2.0-4.0 \mathrm{~mm}$ \\
\hline Stiffness (N/mm) & 4200 & 4600 & $>2000 \mathrm{~N} / \mathrm{mm}$ \\
\hline Air voids in mix (\%) & 3.85 & 3.50 & $3.0-5.0 \%$ \\
\hline $\begin{array}{c}\text { Voids in aggregate } \\
\text { filled with bitumen (\%) }\end{array}$ & 75.00 & 76.50 & $70-80 \%$ \\
\hline
\end{tabular}

\subsection{Surface Condition Results by using Road Scanner (RS)}

Tables 4 and 5 show the analysis of the pavement condition for both CMA and AC14 section based on pavement condition criteria in Table 3. Table 4 and 5 describe that the performance of CMA and $\mathrm{AC} 14$ section for rutting, cracks and texture depth are very impressive which is $100 \%$ in good condition. For roughness, both section show better in good condition. CMA section has highest in roughness which is $94 \%$ compared with AC14 section which is $88 \%$.

Table 3. Pavement condition criteria [17].

\begin{tabular}{|c|c|c|c|c|}
\hline $\begin{array}{c}\text { Condition } \\
\text { criteria }\end{array}$ & $\begin{array}{c}\text { Roughness (IRI), } \\
\mathrm{m} / \mathrm{km}\end{array}$ & $\begin{array}{c}\text { Mean Rut } \\
\text { Depth, mm }\end{array}$ & $\begin{array}{c}\text { Crack } \\
(\% \text { Area })\end{array}$ & $\begin{array}{c}\text { Texture } \\
\text { Depth, mm }\end{array}$ \\
\hline Good & $<2.0$ & $<5.0$ & $<5.0$ & $>0.5$ \\
\hline Fair & $2.0-3.0$ & $5.0-10.0$ & $5.0-10.0$ & $0.3-0.5$ \\
\hline Poor & $3.0-3.8$ & $10.0-20.0$ & $10.0-25.0$ & $<0.3$ \\
\hline Bad & $\geq 3.8$ & $\geq 20$ & $\geq 25$ & N/A \\
\hline
\end{tabular}

Table 4. Pavement condition for CMA section.

\begin{tabular}{|c|c|c|c|c|}
\hline $\begin{array}{c}\text { Condition } \\
\text { criteria }\end{array}$ & Roughness (IRI) & $\begin{array}{c}\text { Mean Rut } \\
\text { Depth }\end{array}$ & Crack & $\begin{array}{c}\text { Texture } \\
\text { Depth }\end{array}$ \\
\hline Good & $94 \%$ & $100 \%$ & $100 \%$ & $100 \%$ \\
\hline Fair & $6 \%$ & $0 \%$ & $0 \%$ & $0 \%$ \\
\hline Poor & $0 \%$ & $0 \%$ & $0 \%$ & $0 \%$ \\
\hline Bad & $0 \%$ & $0 \%$ & $0 \%$ & $0 \%$ \\
\hline
\end{tabular}


Table 5. Pavement condition for AC14 section.

\begin{tabular}{|c|c|c|c|c|}
\hline $\begin{array}{c}\text { Condition } \\
\text { criteria }\end{array}$ & Roughness (IRI) & $\begin{array}{c}\text { Mean Rut } \\
\text { Depth }\end{array}$ & Crack & $\begin{array}{c}\text { Texture } \\
\text { Depth }\end{array}$ \\
\hline Good & $88 \%$ & $100 \%$ & $100 \%$ & $100 \%$ \\
\hline Fair & $12 \%$ & $0 \%$ & $0 \%$ & $0 \%$ \\
\hline Poor & $0 \%$ & $0 \%$ & $0 \%$ & $0 \%$ \\
\hline Bad & $0 \%$ & $0 \%$ & $0 \%$ & $0 \%$ \\
\hline
\end{tabular}

\subsection{Falling Weight Deflectometer (FWD) Test Results}

For this test, both sections exhibit central deflection of below 400 micro meter. Table 7 shows the structural condition analysis based on central deflection classification as shown in Table 6. As shown in Table 7, CMA section has $100 \%$ good condition compare to AC14 which is $95 \%$. It means that CMA section is better in structural condition compare to AC14 section.

Table 6. Central Deflection Classification [17].

\begin{tabular}{|c|c|c|c|}
\hline Range & Good & Fair & Poor \\
\hline Central Deflection $(\mu \mathrm{m})$ & $<400$ & $400-700$ & $>700$ \\
\hline
\end{tabular}

Table 7. Structural condition.

\begin{tabular}{|c|c|c|}
\hline \multirow{2}{*}{ Condition } & \multicolumn{2}{|c|}{ Section } \\
\cline { 2 - 3 } & CMA & AC14 \\
\hline Poor & $0 \%$ & $0 \%$ \\
\hline Fair & $0 \%$ & $5 \%$ \\
\hline Good & $100 \%$ & $95 \%$ \\
\hline
\end{tabular}

\subsection{Skid Resistance Test Result}

Table 8 shows the results recorded for the Skid Resistance Value (SRV) for both sections. Table 8 reveals that CMA section obtain highest SRV which is 63 compare to AC14 which is 60 . Higher SRV represents higher skid resistance. Thus, it shows that surface of CMA section has better resistance comparess to AC14.

Table 8. Summary of British Pendulum Number (BPN).

\begin{tabular}{|c|c|c|c|}
\hline Description & & CMA & AC14 \\
\hline Minimum & & 58 & 56 \\
\hline Maximum & & 68 & 68 \\
\hline Average & & 63 & 60 \\
\hline
\end{tabular}

\subsection{Dynamic Creep Test Results}

Table 9 summarizes dynamic creep test analysis. After a month, it shows that CMA section experiences higher stiffness modulus compares to AC14 section which is $32.01 \mathrm{MPa}$ and 15.73 MPa respectively. It means that CMA section has higher ability to resist rutting. 
Table 9. Summary of Dynamic Creep Test Analysis.

\begin{tabular}{|c|c|c|}
\hline \multirow{2}{*}{ Description } & \multicolumn{2}{|c|}{ Stiffness Modulus (MPa) } \\
\cline { 2 - 3 } & CMA & AC14 \\
\hline Minimum & 24.38 & 13.11 \\
\hline Maximum & 38.14 & 17.63 \\
\hline Average & 32.01 & 15.73 \\
\hline
\end{tabular}

The additional of cup lumps rubber was significant in asphalt mixture due to greater elasticity where it can improve the binder properties and enhance rutting resistance [18]. Based on all the findings, the cup lumps rubber is suitable to be used in asphalt mixtures as a modifier to modified bitumen where it significantly increases the performance.

\section{Conclusions}

It can be concluded that $\mathrm{CMB}$ with $50 \%$ fresh cup lump and $50 \%$ bitumen $60 / 70$ has quite similar performance with PG76. For CMA mixture (5\% CMB), it met PWD specifications and matched with conventional mixture performance. Meanwhile, performance for CMA pavement produced better in surface condition ( $94 \%$ good condition in roughness), structural condition (100\% good condition), skid resistance (SRV 63) and rutting (32.01 MPa) compare to $\mathrm{AC} 14$ pavement.

The authors would like to thanks Universiti Teknologi Malaysia (UTM) for providing the research grant no. R.J130000.7322.4B331 and Q.J130000.2522.17H69.

\section{References}

1. M. E. Abdullah, K. A. Zamhari, R. Buhari, M. N. Nayan, M. R. Hainin, Short term and long term aging effects of asphalt binder modified with montmorillonite 594-595, 9961002 (Key Engineering Materials, 2014)

2. M. K. Idham, M. R. Hainin, H. Yaacob, M. N. M Warid, M. E. Abdullah, Effect of aging on resilient modulus of hot mix asphalt mixtures, 723, 291297 (Key Engineering Materials, 2013)

3. M. E. Abdullah, K. A. Zamhari, M. R. Hainin, E. A. Oluwasola, N. A. Hassan, N. I. M. Yusoff, Const. and Build. Mat. 112, 232240 (2016)

4. J. Ahmad, N. I. M. Yusoff, M. R. Hainin, M. Y. A. Rahman, M. Hossain, Const. and Build. Mat. 50, 567-576 (2014)

5. W. N. A. W. Azahar, R. P. Jaya, M. R. Hainin, M. Bujang, N. Ngadi, Const. and Build. Mat. 126, 218226 (2016)

6. N. A. Hassan, G. D. Airey, N. I. M. Yusoff, M. R. Hainin, R. Putrajaya, M. E. Abdullah, M. M. A. Aziz, Const. and Build. Mat. 82, 173183 (2015)

7. G. Rusbintardjo, M. R. Hainin, N. I. M. Yusoff, Const. and Build. Mat. 49, 702711 (2013)

8. V. Nopparat, P. Jaratsri, N. Nuchanat, Rub. Thai J. 1, 3239 (2012)

9. E. Shaffie, W. W. Hanif, A. K. Arshad, W. Hashim, IOP Conference Series: Materials Science and Engineering 271(1), 012056 (2017, November)

10. M. M. A. Aziz, M. T. Rahman, M. R. Hainin, W. A. W. A Bakar, Const. and Build. Mat. $\mathbf{8 4}, 315319$ (2015) 
11. Z. Sufian, M. S. Mustafa, Proceedings of the Conference on the Use of Rubberised Bitumen in the Road Construction, Selangor, Malaysia (1997)

12. H. H. Mohd, R. Roziawati, Mix Bitumen With Crumb Rubber, Do We Get Rubberised Bitumen, (2013)

13. D. C. Thompson, A. J. Hoiberg, Bituminous Materials: Asphalt Tars and Pitches (Krieger Publishing Co., 1979)

14. Y. Yildirim, Const. and Build. Mat. 21(1), 6672 (2007)

15. A. Samsuri, Proceedings of the Conference on the Use of Rubberised Bitumen in the Road Construction Selangor, Malaysia, 1523 (1997)

16. M. J. Fernando, M. Nadarajah, Rubber Res. Inst. Malay. J. (1969)

17. Ikram Paves Sdn Bhd, Pavement Testing For "Fiber Reinforcement Technology For Asphalt-Trial Lay” at Jalan Kuching, Kuala Lumpur (2015)

18. E. Shaffie, W. W. Hanif, A. K. Arshad, W. Hashim. IOP Conference Series: Materials Science and Engineering 271(1) 012056 (2017, November) 